\title{
Analysis and Visualisation of Research Trends in Photonic Metamaterial: A General Review
}

\author{
Raman Kakkar ${ }^{1}$ \\ ${ }^{1}$ Department of Mechanical Engineering Chandigarh University, Gharuan, Punjab, 140413
}

Article History: Received: 11 January 2021; Accepted: 27 February 2021; Published online: 5 April 2021

\begin{abstract}
Photonic Metamaterials are having wavelengths smaller than the wavelength of light and have diversified applications in sensing and imaging. The bibliometric analysis had been conducted to understand the active authors, organizations, journals, and countries involved in the research domain of "Photonic Metamaterial".All published articles related to "Photonic Metamaterial" from "Scopus", were analyzed using the VOS viewer to develop analysis tables and visualization maps. This article had set the objective to consolidate the scientific literature regarding the "Photonic Metamaterial"and also to find out the trends related to the same.The most active journals in this research domain were Optic Express and Science. The most active countries were China, Germany, and the United States of America. The leading organizations were the Tongji University of China and Karlsruhe Institute of Technology of Germany.The most active authors related to photonicMetamaterials were Linden S., Bade K. and Saile V.

Keywords:Metamaterial,Photonic metamaterial, Bibliometric analysis, VOS viewer,
\end{abstract}

\section{Introduction}

Metamaterials are engineered or composite materials with special or extra features than natural materials. Due to the special nature of metamaterials, the potential usage of metamaterials is diverse including energy, aerospace, medical, infrastructure, and many more[1]. Optical Metamaterials are also known by the name Photonic Metamaterials, with wavelengths smaller than the wavelength of light [2]. Photonic Metamaterials are engineered materials with Nanostructures, dealing with infrared and visible wavelengths[3].Photonic Metamaterials had revolutionized the applicability and usage of optical Metamaterial devices. This new niche branch of science had revolutionized the research in fields of optical sensing, photonic circuits, design optimization, Nanoscale photonic crystals, hyperbolic, optical dielectric, superconducting and quantum, and Nanomechanical photonic Metamaterials and Meta device postulation[3]; effective refracting indexes, negative refractive indexes, transfer optics and polarizers, wave plates and circular dichroic devices[4]mechanically reconfigurable photonic Metamaterials [5].

Photonic Metamaterial isan important research niche in material engineering. This article points out the need for future research regarding Photonic Metamaterials[6]. This bibliometric analysis will be a useful platform for future researchers by realizing the top researchers, organizations, and countries involved in research regarding Photonic Metamaterials. This bibliometric article is arranged in four sections. The first section is the introduction, followed by the discussion of the methodology by which the research was conducted. The third section deals with results and discussion. The fourth section deals with the conclusion

1.1 Research Objectives

a) To consolidate the literature regarding the Photonic Metamaterial

b) To find out the trends related to research in the Photonic Metamaterial

The following research questions are framed for conducting bibliometric analysis systematically.

1.2 Research Questions

a) Who are the active researchers working on the Photonic Metamaterial?

b) Which are the main organizations and countries working on Photonic Metamaterial?

c) Which are the main journals related to Photonic Metamaterial?

\section{Research Methodology}

Scopus files had been used for this article. For the article selection, the Boolean used was TITLE (Photonic Metamaterial) on 05/01/2020. All the tables in this paper were created by using Microsoft Excel and VOS Viewer. Grammarly was used for spelling and grammar checks. Mendeley was used for article review and citation. This paper had been inspired by bibliometric analysis in its presentation style, analysis, and methodology from the works[7][8][9][10].

\section{Results and discussion}

1.1 Results

This first round of search produced an outcome of 548 documents, intwolanguages, out of which 536 documents were in English and the rest were in Chinese. The classification of document categories is shown in Figure 1. For improving the quality of the analysis, we had selected only the peer-reviewed articles and all other documents had not been considered. Thus after using filters "Article"and "English" the second round search 
produced an outcome of 285 English articles (both open access and others) andhad been used to conduct bibliometric analysis and visualization using VOS Viewer. The English research articles in this domain since 2002 had been shown in Figure 2.

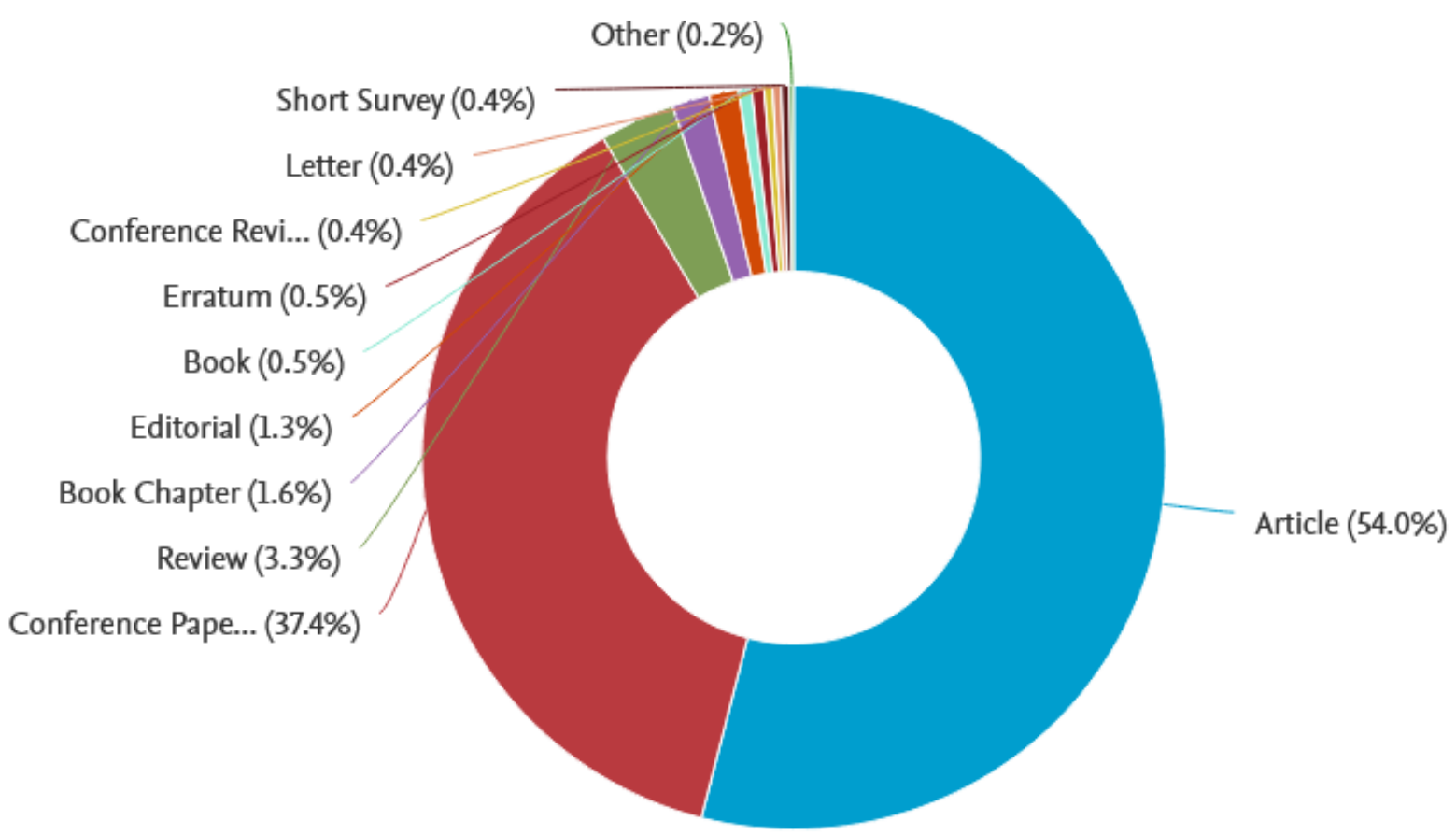

Figure 1: Classification of the documents on "Photonic Metamaterial", Source: www.scopus.com

35

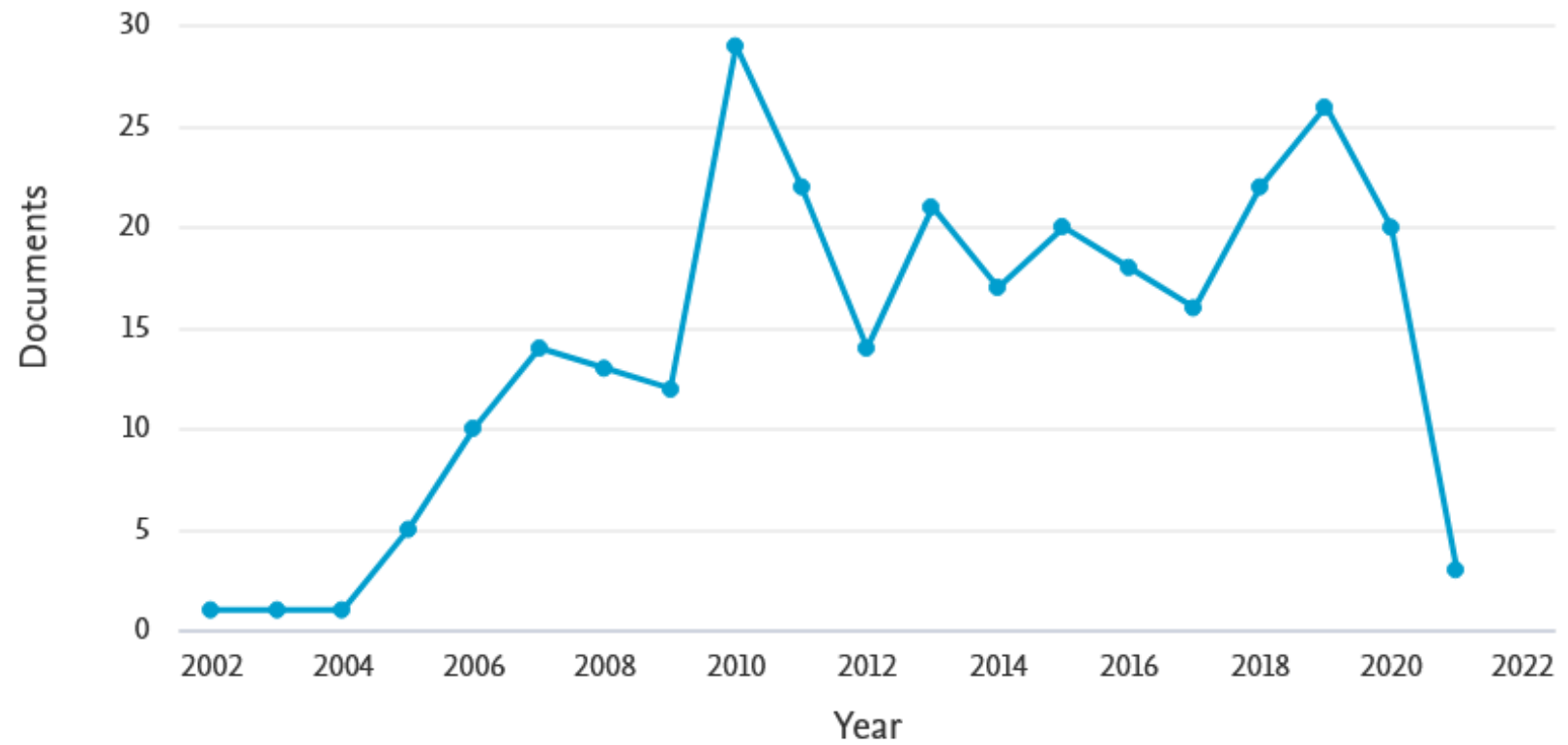

Figure 2: Period wise publication of articles, Source: WWW.scopus.com

Co-authorship analysis of top authors had been shown in figure 3. For a better presentation of the analysis, the parameters used were the minimum number of documents of an author as fiveand the minimum number of citations of authors as one. This combination plotted the map of 27 authors, in nine clusters. The overlay visualization map of co-authorship analysis plotted in Figure 3, points out the major researchers with their strong co-authorship linkages and clusters involved. 


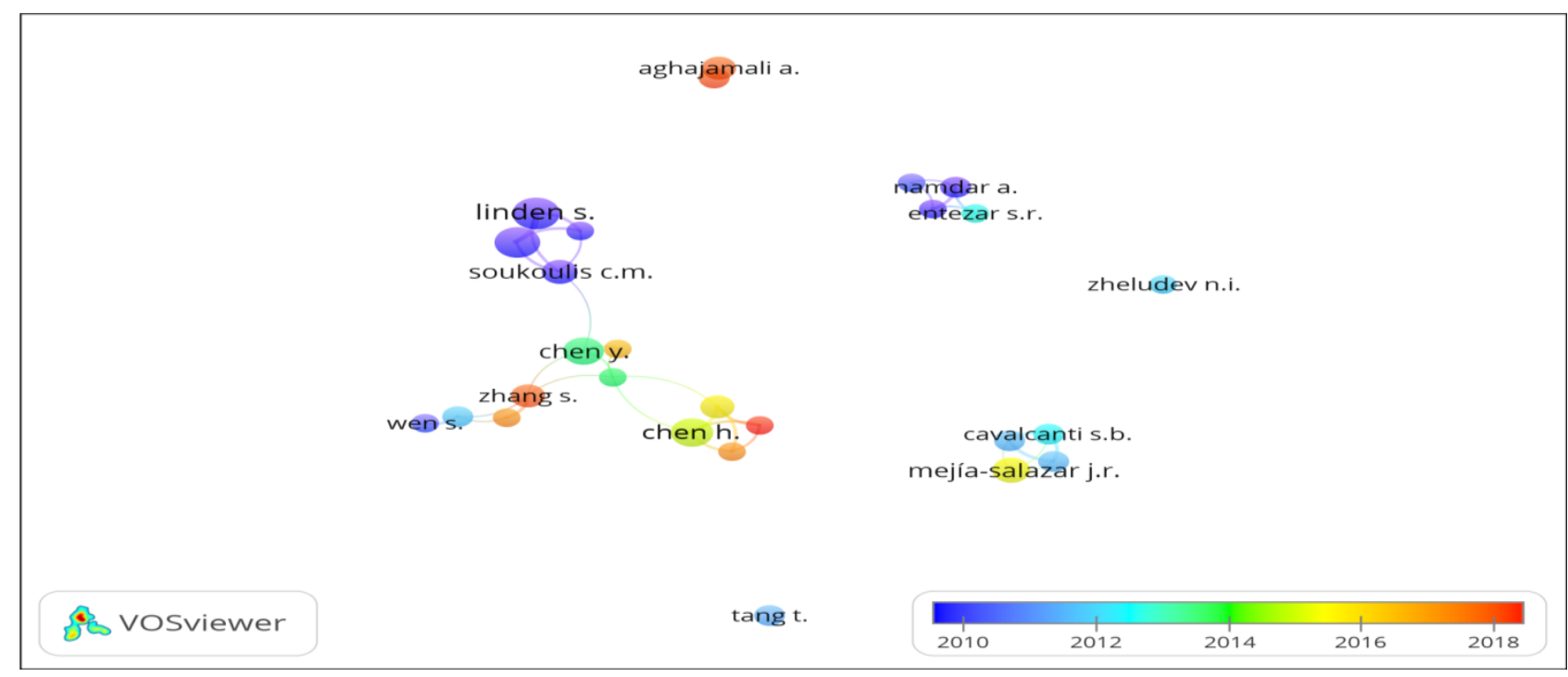

Figure 3: Co-authorship analysis on basis of authors

The citation analysis of top authors had been shown in table 1, along with co-authorship links.For the citation analysis, the parameters used werethe minimum number of documents of an author as one and the minimum citations of an author as one.

Table 1: Highlights of most active authors

\begin{tabular}{|c|c|c|c|c|c|}
\hline Description & Authors & $\begin{array}{l}\text { Documen } \\
\text { ts }\end{array}$ & ns & $\begin{array}{l}\text { Average } \\
\text { citations per } \\
\text { documents }\end{array}$ & $\begin{array}{l}\text { Link } \\
\text { strength }\end{array}$ \\
\hline $\begin{array}{l}\text { Authors with the } \\
\text { highest publication, } \\
\text { citation, and co- } \\
\text { authorship links }\end{array}$ & Linden $\mathrm{S}$. & 14 & 3403 & 243.07 & 70 \\
\hline Authors with the & Bade K. & 1 & 1695 & 1695 & 8 \\
\hline highest average citation & Saile V. & 1 & 1695 & 1695 & 8 \\
\hline
\end{tabular}

In Co-occurrence analysis, we had used all keyword analyses, by keeping the minimum number of occurrences of a keyword asten. This combination plotted the map of 33thresholds, in fourclusters. The overlay visualization of co-occurrence analysis of keywords has been shown in Figure 4.

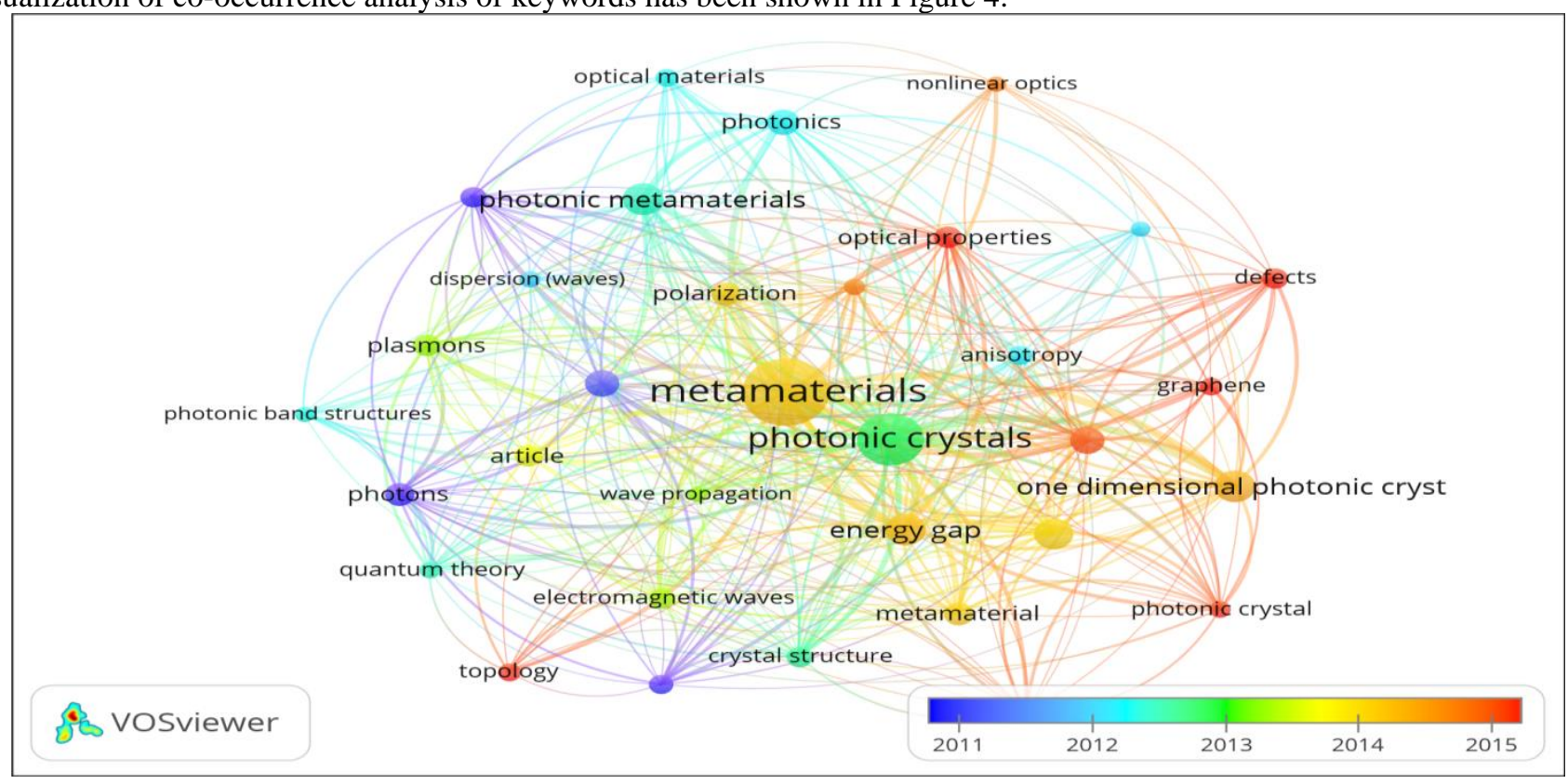

Figure 4: Co-occurrence analysis on basis of all keywords

The leadingorganizations engaged in research on "Photonic Metamaterial" had been found out by the volume of publications and citation analysis, the parameters used are the minimum number of documents of an 
organization as one and the minimum number of citations of organizations as one. This combination plotted the map of 531organizations, in 191clusters.

The leading organization in the research regarding "Photonic Metamaterial", with the highest number of publications and citations,were the Tongji University of China and Karlsruhe Institute of Technology of Germany(Refer to table 2).

Table 2: Highlights of the most active organization

\begin{tabular}{|c|c|c|c|c|}
\hline Organizations & Country & Documents & ${ }_{\mathrm{ns}}$ Citatio & \begin{tabular}{l}
\multicolumn{2}{c}{ Average } \\
Citations per \\
document
\end{tabular} \\
\hline Tongji University & China & 15 & 194 & 13 \\
\hline $\begin{array}{l}\text { Karlsruhe Institute of } \\
\text { Technology }\end{array}$ & Germany & 12 & 3193 & 274.4 \\
\hline
\end{tabular}

Co-authorship analysis of the countries engaged in the research on "Photonic Metamaterial" had been shown in Figure 5. For a better presentation of the analysis, the parameters used were the minimum number of documents of an author as three and the minimum number of citations of authors as one. This combination plotted the map of 27 countries,nineclusters. The overlay visualization map of co-authorship analysis plotted in Figure 5, points out the main countries with their strong co-authorship linkages and clusters involved.

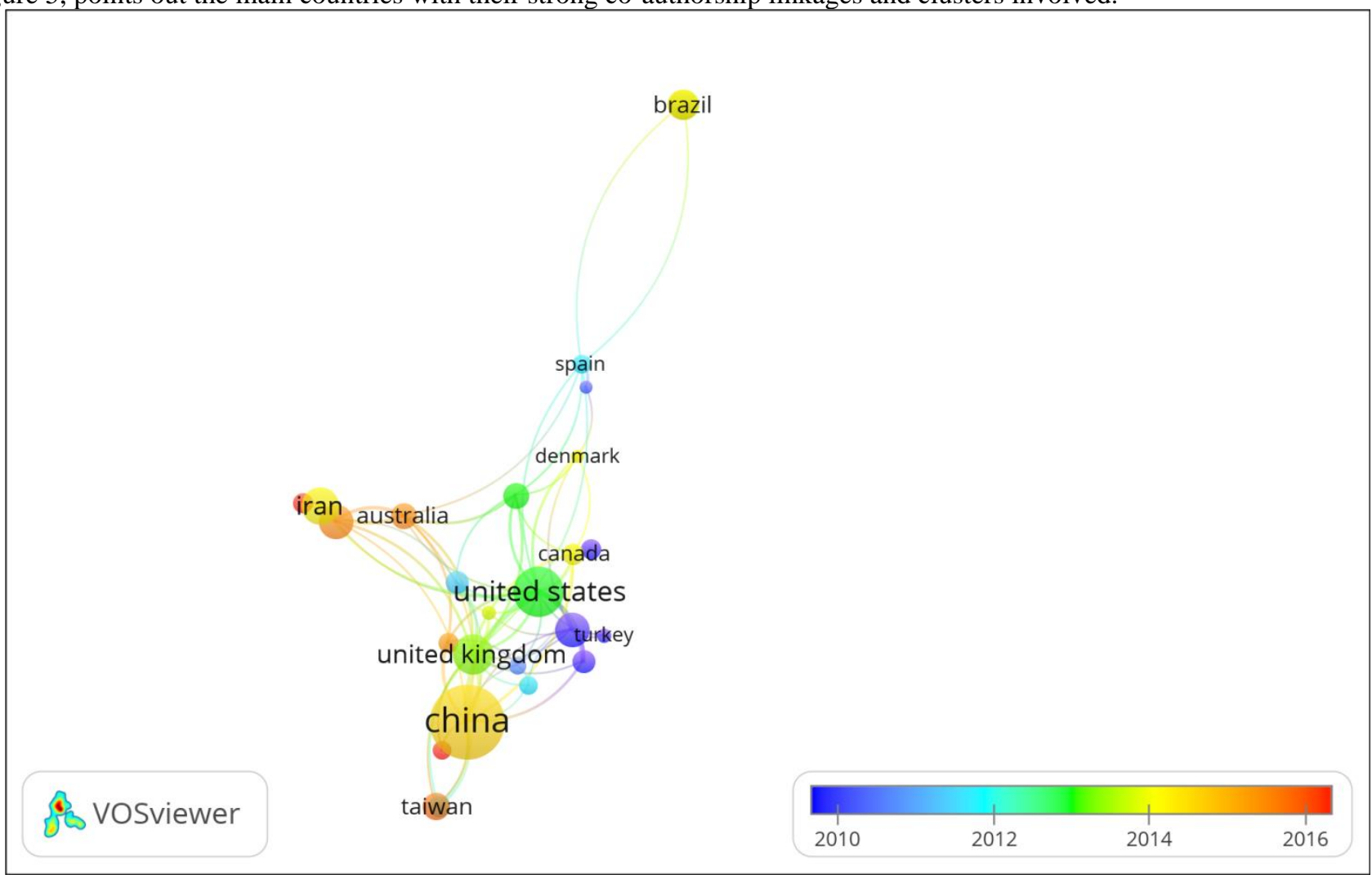

Figure 5: Co-authorship analysis on basis of countries

The citation analysis of top countries had been shown in table 3, along with co-authorship links. For the citation analysis, the parameters used were the minimum number of documents of acountry as one and the minimum citations of the country as one.

Table 3: Highlights of Active Countries

\begin{tabular}{|c|c|r|r|r|r|}
\hline Description & Country & Documen & Citatio & \multicolumn{1}{|c|}{$\begin{array}{c}\text { Average } \\
\text { citations } \\
\text { documents }\end{array}$} & $\begin{array}{c}\text { Link } \\
\text { per }\end{array}$ \\
strength \\
$\begin{array}{c}\text { The country with the } \\
\text { highest publication }\end{array}$ & China & 92 & 1461 & 15.88 & 34 \\
\hline $\begin{array}{c}\text { The country with the } \\
\text { highest co-authorship links }\end{array}$ & $\begin{array}{l}\text { United } \\
\text { States of } \\
\text { America }\end{array}$ & 43 & 2487 & & \\
\end{tabular}




\begin{tabular}{|l|l|r|r|r|r|}
\hline $\begin{array}{l}\text { The country with the } \\
\text { highest citations and average } \\
\text { citations }\end{array}$ & Germany & 20 & 4513 & & \\
\end{tabular}

The most active countries in this research domain were China, Germany,andthe United States of America with the highest number ofpublications, citations, and co-authorship links respectively.

Link analysis and citation analysis were used to identify the most active journal in this research domain. We have taken the parameters of the minimum number of documents of a journal as one and the minimum number of citations of a journal as one for the link analysis and citation analysis. Highlights of the most active and relevant journals related to the "Photonic Metamaterial"are shown in table 4. Table 4shows the journal activity of this research domain through parameters of publication volume, citations, and co-authorship linkages. Optic expresswas the most active journal with the highest publications, co-authorship,and citations.The leading journal with the highest average citation is Science.

Table 4: Analysis of journal activity

\begin{tabular}{|c|r|r|r|r|r|}
\hline Description & Journal details & Documen & Citatio & $\begin{array}{c}\text { Average } \\
\text { citations per } \\
\text { documents }\end{array}$ & $\begin{array}{r}\text { Link } \\
\text { strength }\end{array}$ \\
\hline $\begin{array}{c}\text { Journal with the } \\
\text { highest publications, } \\
\text { citations, and co- } \\
\text { authorship links }\end{array}$ & Optics Express & 22 & 908 & 41.27 & 38 \\
\hline $\begin{array}{c}\text { Journal with the } \\
\text { highest average citation }\end{array}$ & Science & 1 & 1695 & 1695 & 14 \\
\hline
\end{tabular}

From the above discussion regarding the bibliometric patterns in the research regarding the Photonic Metamaterial,this research had observed a gradual increase in research interest regarding the Photonic Metamaterial from the starting of the millennium and the momentum is going on positively. This points out the relevance and potential of this research domain (Refer to Figure 2). The most active authors in this research domainwere Linden S.with the highest publication, citations, and co-authorship links. Bade K., and Saile V with the highest average citations (Refer to table 1). The overlay analysis of top countries researching Photonic Metamaterialindicates that China, Germany, and the United States of Americawere the leading country in research regarding Photonic Metamaterialwith the highest publications, citations, and co-authorship links(Refer to figure 5). The top journals of this research domain were identified as Optic Express and science. Fromthese wide sources of information, researchers can focus on top journals where they can identify the most relevant and highly cited articles regarding Photonic Metamaterials.

\section{Conclusion}

The Photonic Metamaterialis an interesting research domain and the most active journals related to this research domain are Optic Express and Science. The most activecountrieswere China, Germany, andthe United States of America.The leading organizations engaged in the research regarding Photonic Metamaterialwerethe Tongji University of China and Karlsruhe Institute of Technology of Germany. The most active authors who had made valuable contributions related to photonicMetamaterialswere Linden S., Bade K. and Saile V. This research domain offers a new avenue for researchers and future research can be on Metamaterial, Optical designing[11], and applications of Photonic Metamaterial.

\section{References}

A. M. Berger, "What are metamaterials?," Nanowerk, 2020. .

B. S. Linden et al., "Photonic Metamaterials: Magnetism at Optical Frequencies," IEEE J. Sel. Top. Quantum Electron., vol. 12, no. 6, pp. 1097-1105, Nov. 2006.

C. X. C. Tong, "Photonic Metamaterials and Metadevices," in Functional Metamaterials and Metadevices, Springer Series in Materials Science book series, 2017, pp. 71-106.

D. M. Iwanaga, "Photonic metamaterials : a new class of materials for manipulating light waves," Sci. Technol. Adv. Mater., vol. 13, no. 5, 2012.

E. and N. I. Z. J. Y. Ou, E. Plum, L. Jiang, "Reconfigurable Photonic Metamaterials," Nano Lett., vol. 11, no. 5, pp. 2142-2144, 2011.

F. K. M. Batoo et al., "Structural, morphological and electrical properties of $\mathrm{Cd} 2+$ doped $\mathrm{MgFe} 2-\mathrm{xO} 4$ ferrite nanoparticles," J. Alloys Compd., vol. 726, pp. 179-186, 2017.

G. S. Arunachalam, M. K. Dhirendra Rao, and P. K. Shrivastava, "Physics research in Israel—A preliminary 
bibliometric analysis,” J. Inf. Sci., vol. 8, no. 5, pp. 185-195, 1984.

H. S. Ahn, J. Kang, and H. J. Lee, "Research trends in condensed matter physics based on bibliometric analysis," Information, vol. 14, no. 5, pp. 1745-1760, 2011.

I. X. Wang, Z. Xu, S.-F. Su, and W. Zhou, "A comprehensive bibliometric analysis of uncertain group decision making from 1980 to 2019,” Inf. Sci. (Ny)., vol. 547, pp. 328-353, 2021.

J. N. Niknejad, W. Ismail, M. Bahari, R. Hendradi, and A. Z. Salleh, "Mapping the research trends on blockchain technology in food and agriculture industry: A bibliometric analysis," Environ. Technol. Innov., vol. 21, 2021.

K. U. Singh, R. Salgotra, and M. Rattan, “A Novel Binary Spider Monkey Optimization Algorithm for Thinning of Concentric Circular Antenna Arrays," IETE J. Res., vol. 62, no. 6, pp. 736-744, 2016. 